\title{
Reduction of Perinatal Hypoxic-Ischemic Brain Damage with Allopurinol
}

\author{
CHARLES PALMER, ROBERT C. VANNUCCI, AND JAVAD TOWFIGHI \\ Departments of Pediatrics (Neonatology [C.P.] and Neurology [R.C.V.]) and of Pathology (Neuropathology \\ [J.T.J). The Milton S. Hershey Medical Center of The Pennsylvania State University, Hershey, \\ Pennsylvania 17033
}

\begin{abstract}
Cytotoxic free radicals are generated during cerebral hypoxia-ischemia and reperfusion. We studied the efficacy of allopurinol, a xanthine oxidase inhibitor and free radical scavenger, in reducing posthypoxic-ischemic damage in the developing brain of 7-d-old rat pups. Hypoxic-ischemic injury to the right cerebral hemisphere was produced by ligation of the right common carotid artery followed by $3 \mathrm{~h}$ of hypoxia with $8 \%$ oxygen. Thirty to 45 min before the hypoxia, the rats received either allopurinol $($ dose $=130-138 \mathrm{mg} / \mathrm{kg})$ or an equal vol of saline $(0.2 \mathrm{~mL})$. Some pups were killed at $42 \mathrm{~h}$ of recovery for measurement of cerebral hemispheric water content, whereas others were killed at $\mathbf{3 0}$ or more $\mathbf{d}$ for neuropathologic examination. A total of 18 allopurinol treated rats had significantly less water content in the right hemisphere $(89.07 \pm 0.32 \%)$ than 23 saline-treated animals $(91.64 \pm 0.25 \%$, mean \pm SEM, $p<0.0001$ ). Rank scoring of neuropathologic alterations revealed that the allopurinol treated rats were less damaged $(p=0.001)$. Only two of 13 brains from the allopurinol group suffered infarction compared to 10 of the 14 saline-treated animals. The results indicate that allopurinol reduces both cerebral edema and the extent of perinatal hypoxic-ischemic brain damage. (Pediatr Res 27: 332-336, 1990)
\end{abstract}

Free radicals contribute to the pathogenesis of hypoxicischemic brain damage (1-5), and successful management of traumatic or ischemic brain injury includes prevention of free radical damage (6-10).

During cerebral hypoxia-ischemia, tissue stores of ATP are degraded sequentially to ADP, AMP, adenosine, inosine, and hypoxanthine $(11,12)$. Hypoxanthine levels accumulate as further metabolism is impeded by tissue hypoxia $(13,14)$. During reperfusion and reoxygenation, there is a transient rise in xanthine with a concomitant fall in hypoxanthine, reflecting the conversion of hypoxanthine to xanthine by the enzyme xanthine oxidase (15). This reaction generates superoxide and secondarily derived cytotoxic species including hydroxyl radicals (2). Free radicals are highly reactive molecules capable of damaging cells by peroxidation of membrane phospholipids (16) and by oxidation of cellular proteins and nucleic acids (17).

Allopurinol is both an inhibitor of xanthine oxidase (18) and a scavenger of free radicals $(19,20)$. It has been used successfully to reduce ischemic injury of the heart (21), kidney (22), small intestine (23), and adult rat brain $(24,25)$. Accordingly, we

Received August 21, 1989; accepted November 17, 1989

Correspondence: Dr. Charles Palmer, Department of Pediatrics, The Milton S Hershey Medical Center, The Pennsylvania State University, P.O. Box 850, Hershey, PA 17033.

Supported by Grant HD 19913 from The National Institute of Child Health and Human Development. aimed to establish if allopurinol could reduce hypoxic-ischemic injury to the developing brain of the 7-d-old rat pup.

\section{MATERIALS AND METHODS}

To evaluate the potential neuroprotective effect of allopurinol, we studied 7-d postnatal rat pups in which we induced a hypoxicischemic insult to the right cerebral hemisphere (see below). Animals were killed after either a short $(42 \mathrm{~h})$ or long $(30 \mathrm{~d})$ period of recovery to evaluate the extent of the lesion.

Animals in the short recovery study were evaluated for brain water content, whereas those in the long recovery study were killed after $30 \mathrm{~d}$ of age to evaluate long-term neuropathologic alterations. The rat pups were treated alternately with either saline or allopurinol (see below).

Animal model. Seven-d-old Wistar (Charles River, Wilmington, MA) rat pups of either sex, weighing between 12-18 g were anesthetized with a mixture of halothane ( $4 \%$ halothane, $1-1.5 \%$ for maintenance), $30 \%$ oxygen, and balance nitrous oxide. The right common carotid artery of each pup was ligated with 4-0 surgical silk. The wound was then sutured and the animal allowed to recover. The duration of anesthesia was about $5 \mathrm{~min}$. After surgery, the rat pups were returned to their dams for $2 \frac{1 / 2}{h}$. Pups from mixed litters were then randomly divided into two equal treatment groups. One group received an injection of normal saline $(0.2 \mathrm{~mL})$ given s.c. into the back. The other group received $2 \mathrm{mg}(0.2 \mathrm{~mL})$ of allopurinol (Zyloprim sodium, Burroughs Wellcome Co., Research Triangle Park, NC). Zyloprim, the sodium salt of allopurinol, after dilution to $10 \mathrm{mg} / \mathrm{mL}$ with sterile water, had a $\mathrm{pH}$ of 11.5. To permit absorption and distribution of allopurinol, the animals were allowed to recover for another $30 \mathrm{~min}$ after injection before being exposed to cerebral hypoxia-ischemia (see below).

A previous study (24), supported by limited experiments in our laboratory, suggested a dose in excess of $100 \mathrm{mg} / \mathrm{kg}$ was needed to demonstrate a neuroprotective effect. The dose used in this study was limited by injection volume and by the occurrence of subcutaneous hemorrhages if higher concentrations of allopurinol were used.

As each pup received the same amount of allopurinol $(2 \mathrm{mg})$, variations in animal wt would have caused minor differences in the $\mathrm{mg} / \mathrm{kg}$ dose per animal. The average amount of allopurinol received by the 63 pups in the short recovery and 35 pups in the long recovery study was 138 and $130 \mathrm{mg} / \mathrm{kg}$, respectively.

Inasmuch as allopurinol has an alkaline $\mathrm{pH}$, the acid base status of eight allopurinol-treated pups was compared with eight saline-treated pups. Blood was collected from severed neck vessels $1 \mathrm{~h}$ after s.c. allopurinol $(135 \mathrm{mg} / \mathrm{kg})$ or an equivalent vol of saline.

Allopurinol did not cause a significant alteration in acid base status. The allopurinol group had a pH of $7.31 \pm 0.09$ (mean \pm $\mathrm{SEM})$ versus $7.26 \pm 0.04$ in the saline-treated group $(p=0.19)$. 
Bicarbonate levels were $21.2 \pm 4.9$ and $18.9 \pm 2.9$ in the allopurinol and saline groups, respectively ( $p=0.27$ ).

Four rat pups (two from each treatment group) were placed in each of four $500-\mathrm{mL}$ airtight jars and exposed to an $8 \%$ oxygen$92 \%$ nitrogen mixture (26). The jars were partially submerged in a $37^{\circ} \mathrm{C}$ water bath to maintain a constant thermal environment. Air temperature in the jar was measured at $32^{\circ} \mathrm{C}$. After $3 \mathrm{~h}$ of hypoxia, the jars were opened to room air and the surviving pups returned to their dams. Survival was defined as spontaneous recovery in air after $3 \mathrm{~h}$ of hypoxia. This insult is known to produce selective neuronal necrosis or infarction restricted to the cerebral hemisphere ipsilateral to the common carotid artery ligation (26).

Brain swelling: water content. After $42 \mathrm{~h}$ of recovery with their dams, the pups were decapitated and their brains removed. A portion $(150-200 \mathrm{mg})$ from the posterior half of each cerebral hemisphere was placed in a preweighed 5-mL glass vial and then reweighed on a microanalytical balance. The posterior half of the right hemisphere (ipsilateral to common carotid artery ligation) represented the area most severely injured, whereas the corresponding area in the left hemisphere served as control. Subsequently, the specimen was dessicated at $70^{\circ} \mathrm{C}$ for $48-72 \mathrm{~h}$. Reweighing ascertained the dry wt of the tissue, and by subtraction from the wet wt the water content of the hemisphere was obtained. Water content was determined as a percentage of wet wt according to the formula:

$$
\text { water content }(\mathrm{WC} \%)=\frac{\text { wet wt }- \text { dry wt }}{\text { wet wt }} \times 100
$$

In a separate experiment, twelve 9-d-old rat pups, which were neither ligated nor rendered hypoxic, served as controls. Water content was measured when the pups were the same age as the experimental animals at $42 \mathrm{~h}$ of recovery. Water content for each hemisphere was determined as above.

Neuropathologic procedures. To examine long-term neuropathologic outcome, 35 rat pups were carotid artery ligated and rendered hypoxic in the manner described above. However, for this study, allopurinol was given $45 \mathrm{~min}$ before hypoxia in an effort to achieve better drug distribution. At the end of the hypoxic exposure, surviving animals were returned to their dams. Treatment groups were identified by clipping the tip of the tail or cutting a small notch in the right ear. These procedures incurred minimal bleeding.

At $30-44 \mathrm{~d}$ of recovery the animals were killed with a lethal dose of pentobarbital $(150 \mathrm{mg})$. The brains were carefully removed from the skull and immediately placed in formaldehyde, acetic acid, and methanol, 1:1:8.

Individual brains were later grouped into one of four categories based on the gross morphologic appearance of the right cerebral hemisphere (normal, mild, moderate, severe) (Fig. 1). (Recall that it is the right common carotid artery which was occluded.) Normal referred to no difference in size between the two hemispheres; mild referred to some discrepancy in size between hemispheres with right side smaller than left without any visible infarct; moderate indicated marked discrepancy in size due to a large infarct in the right hemisphere with some preservation of the posterior aspect; and severe related to extensive infarction of the right hemisphere with almost total destruction of its posterior aspect. The anteromedial aspect of the right cerebral hemisphere was always spared even in the severe group.

Two examiners (R.C.V. and J.T.) allocated the brains into one of the four pathologic categories. Examiners were blinded to treatment and were unaware of each other's findings. After grouping, the brains were ranked by each examiner in ascending order of severity and the rankings compared.

After the brains were categorized and ranked according to gross pathology, two brains from each category (one from each treatment group) were examined histologically. This was done to evaluate the microscopic characteristics of each category and
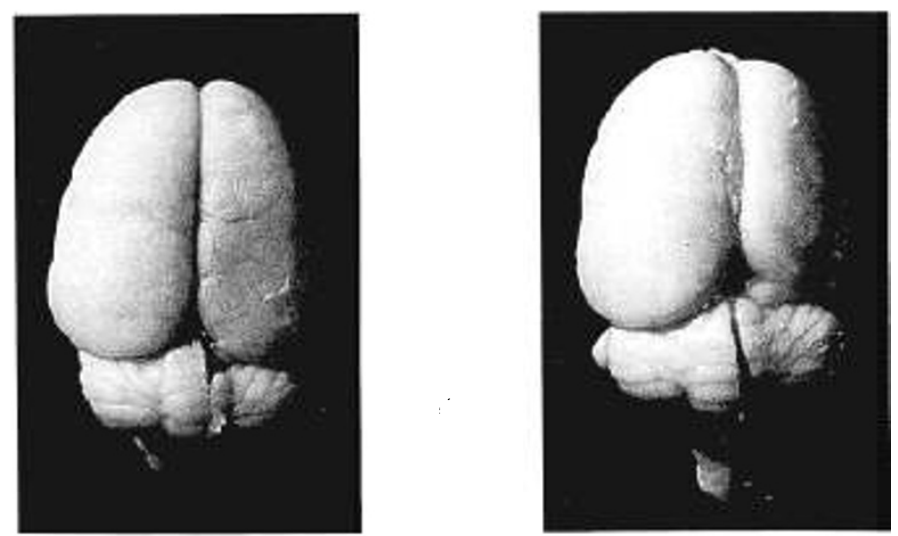

Normal

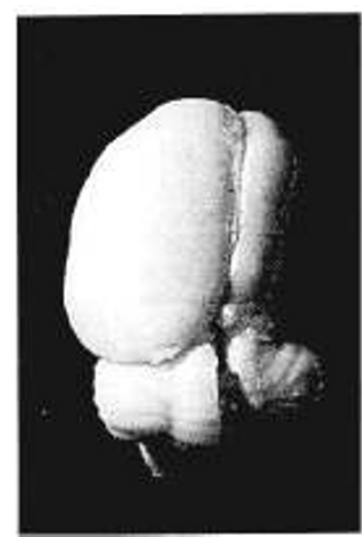

\section{Moderate}

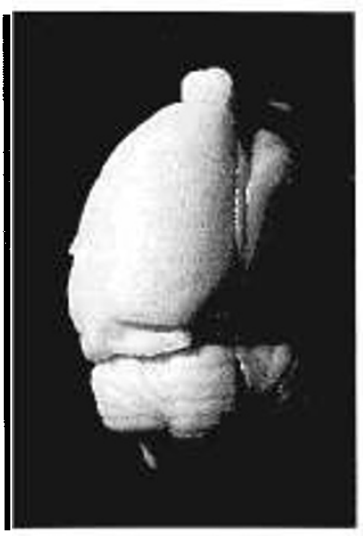

Fig. 1. Dorsal view of representative rat brains in four distinct categories. Normal: symmetric cerebral hemispheres; mild: atrophic right hemisphere; moderate: large infarct with relative preservation of medial aspect of right hemisphere; severe: extensive infarct of right hemisphere including the entire posterior medial aspect.

to establish if the nature of damage was the same in the two treatment groups. Seven brains were selected (as the brains in the moderate category were all from the saline group, only one was chosen from that category). The brains were coronally cut into 1- to 2-mm slices and then embedded entirely in paraffin for sectioning and staining with hematoxylin and eosin.

Statistical analyses. We used the two-tailed Student's $t$ test, Fischer exact test or Mann-Whitney $\mathrm{U}$ test where appropriate. $p$ $<0.05$ was considered significant. The survival studies were analyzed with the Cochran-Mantel-Haenszel statistic and the Breslow-Day test.

\section{RESULTS}

Survival studies. In the short-term recovery study, 13/31 (41\%) of the allopurinol-treated pups died. The 18 survivors generated an odds for dying ratio of $13 / 18(0.72)$. In the same study, $9 / 32$ $(28 \%)$ of the saline treated pups died. The 23 survivors generated an odds for dying ratio of $9 / 23(0.39)$. The survival odds for the allopurinol- and saline-treated pups were not significantly different ( $p=0.25$, Cochran-Mantel-Haenszel statistic).

In the long-term recovery study $6 / 19(32 \%)$ of the allopurinoltreated pups died. The 13 allopurinol survivors made the odds for dying $6 / 13(0.46)$. In the saline treated, $1 / 16(1 \%)$ died. The 15 survivors made the odds for dying $1 / 15(0.03)$. The difference 
in survival odds for the two treatment groups in this study was not statistically significant ( $p=0.07$, Cochran-Mantel-Haenszel statistic).

As more allopurinol-treated pups died in the long-term study compared to the short-term study, we compared the survival data between studies to find that they were not statistically different ( $p=0.28$ Breslow-Day test).

Animal wt. The wt of the pups at $7 \mathrm{~d}$ of age were compared for treatment group and survival outcome. In the short-term recovery study, the average wt was $14.47 \pm 0.19 \mathrm{~g}$ (mean \pm SEM). Wt were the same for treatment groups and for survival outcome ( $p=0.37$ analysis of variance). In the long-term recovery study the average rat pup weighed $15.39 \pm 0.25 \mathrm{~g}$ (mean \pm SEM). The 13 allopurinol survivors and six nonsurvivors weighed the same as the 15 saline survivors $(p=0.39$ analysis of variance).

Water content. The cerebral hemisphere ipsilateral to the carotid artery ligation in the allopurinol treated pups had a lower water content $(89.07 \pm 0.32 \%$, mean \pm SEM) than the salinetreated pups where water content was $91.64 \pm 0.25 \%(p<$ 0.0001 ) (Table 1). The water content of the left hemisphere (contralateral to the ligation) of both the allopurinol and salinetreated pups was unchanged from the control values of nonligated, nonhypoxic rat pups.

Gross neuropathology. From among the 13 surviving allopurinol-treated and 15 surviving saline-treated pups, one salinetreated pup died during the long-term recovery period. Two examiners (R.C.V. or J.T.), blinded to treatment, grouped each of the fixed brains of 27 surviving pups into one of four categories: normal, mild, moderate, severe. The results of the first examiner are illustrated in Table 2 . Significantly less damage was seen in the allopurinol treated pups (Fisher exact $p=0.005$ ). Only two of 13 allopurinol-treated pups had more than mild damage, whereas 10 of 14 saline-treated animals fell into the

Table 1. Water content as percentage of cerebral hemisphere wt in control and experimental (hypoxic-ischemic) rat pups pretreated with allopurinol or saline*

\begin{tabular}{|c|c|c|}
\hline \multirow{2}{*}{ Group } & \multicolumn{2}{|c|}{$\begin{array}{c}\text { Cerebral hemispheric water content } \\
\%\end{array}$} \\
\hline & Ipsilateral (R) & Contralateral (L) \\
\hline Controls $(n=12)$ & $87.72 \pm 0.06$ & $87.71 \pm 0.04$ \\
\hline \multicolumn{3}{|l|}{ Experimental } \\
\hline Allopurinol $(n=18)$ & $89.07 \pm 0.32 \dagger \neq$ & $87.66 \pm 0.16$ \\
\hline Saline $(n=23)$ & $91.64 \pm 0.25$ & $87.85 \pm 0.09$ \\
\hline
\end{tabular}

$*$ Values are mean \pm SEM for the numbers of animals in parentheses. Controls were subjected to neither ligation nor hypoxia. Experimental rats were subjected to right (ipsilateral) carotid ligation and $3 \mathrm{~h}$ of hypoxia with $8 \%$ oxygen.

$\dagger$ Significantly different from saline treated at $p<0.0001$ (two-tailed, unpaired Student's $t$ test)

$\ddagger$ Significantly different from controls at $p<0.01$.

Table 2. Neuropathologic grading*†

\begin{tabular}{ccc}
\hline Gross pathologic category & \multicolumn{2}{c}{ Treatment group } \\
\cline { 2 - 3 } & $\begin{array}{c}\text { Allopurinol } \\
\text { (no. of } \\
\text { animals) }\end{array}$ & Saline \\
\hline Normal & 7 & 1 \\
Mild & 4 & 3 \\
Moderate & 0 & 5 \\
Severe & 2 & 5 \\
\hline
\end{tabular}

\footnotetext{
$* p=0.005$ (two-tailed Fisher's exact).

$\dagger$ Neuropathologic grading performed by first examiner. Second examiner differed from above in that one allopurinol animal in the mild category was called normal and one saline in the severe group was called moderate. $p=0.012$ Fisher's exact.
}

moderate or severe categories characterized by marked atrophic and cystic damage. The second examiner confirmed that the allopurinol treated were less damaged $(p=0.012)$. This categorization differed from the first examiner only slightly (see legend to Table 2).

The brains were also ranked in order of severity and the sum of the ranks compared. The examiners concurred that the allopurinol treated animals were significantly less damaged ( $p=$ 0.001 , Mann-Whitney U).

Histopathology. The normal category showed no abnormalities. Alterations of the right cerebral cortex in the mild category included thinning of the cerebral cortex. The cortical thickness was reduced to two-thirds to three-fourths normal size in the middle cerebral artery territory due to neuronal loss and gliosis in a roughly columnar fashion with marked shrinkage of the hippocampus due to severe neuronal loss and gliosis with only parts of the fascia dentata remaining (Fig. 2). There were also patchy areas of neuronal loss and gliosis present in the dorsolateral and ventroposterior thalamic nuclei. The moderate category had extensive cystic infarction of the right hemisphere involving cerebral cortex and white matter (anterior, superior, and medial aspects of the frontal lobe was relatively spared), the entire hippocampus, amygdaloid nucleus, basal ganglia, and the dorsolateral thalamus. Septal nuclei had only patchy loss of neurons and gliosis. The right superior colliculus was mildly atrophic, and the right pyramidal tract in the brainstem was small. In the severe category, the right cerebral hemisphere was virtually totally destroyed and replaced by a cystic infarct with the exception of a small rim of cortex medially and anteriorly as well as the medial hypothalamus. There was a small strip of neuronal loss and gliosis in the supracallosal cortex bilaterally, with the lesion on the right side being larger. There was also moderate to marked atrophy of the right superior colliculus and pyramidal tract.

\section{DISCUSSION}

The results of our study show that allopurinol substantially reduces hypoxic-ischemic brain damage in 7-d-old rat pups. In this perinatal model, brain swelling and infarction are produced by a combination of hypoxia and ischemia. These dual insults are necessary as carotid artery ligation or hypoxia alone is unable to cause injury (26).

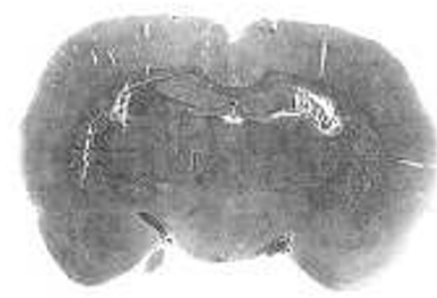

Normal

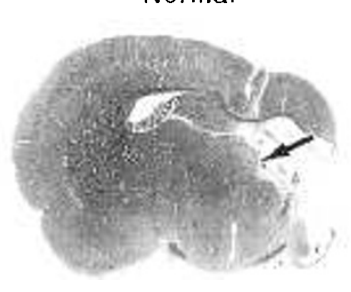

Moderate

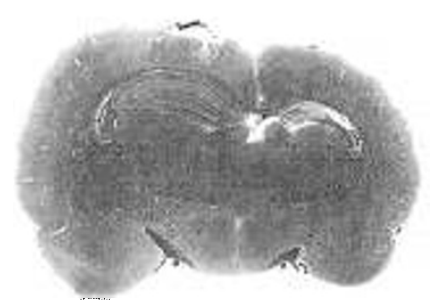

Mild

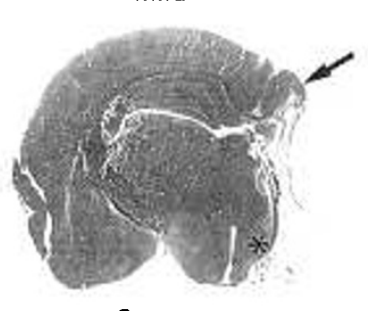

Severe
Fig. 2. Coronal sections at infundibular level of representative rat brains from the four categories (compare with Fig. 1). Normal; mild: atrophy of the right hemisphere; moderate: large cystic infarct extending deep and involving dorsolateral thalamus (arrow); severe: extensive infarct with almost total destruction of the right hemisphere with preservation of a small rim of cortex dorsomedially (arrow) and medial hypothalamus (asterisk). (Hemotoxylin and eosin stain, magnification $4 \times$.) 
Allopurinol, an analog of hypoxanthine, inhibits xanthine oxidase by virtue of its own substrate activity with this enzyme. The product of the reaction, oxypurinol, is a noncompetitive inhibitor of xanthine oxidase and produces a stable complex with the enzyme. Allopurinol and oxypurinol are distributed in total body water, with the exception of brain, in which their concentrations are approximately one-third those of other tissues. Neither compound is bound to plasma proteins (27).

We chose to measure cerebral water content at $42 \mathrm{~h}$ of recovery from hypoxia-ischemia as previous work in our laboratory had shown that edema is well-established at this interval (28). The vasogenic component of cerebral edema requires injury to the capillary endothelial cell, which then allows macromolecules, e.g. albumin, and water to pass through the blood-brain barrier (29). Cerebral capillary endothelial cells may be particularly susceptible to free radical attack because xanthine oxidase is concentrated 3.7 times within these cells compared to a homogenate of rat cerebral cortex (30). Zweier et al. (31) showed that endothelial cells are potent sources of cytotoxic superoxide and hydroxyl free radicals. They demonstrated that xanthine oxidase was the source of free radicals and that free radical generation could be inhibited with allopurinol and oxypurinol. Chan et al. (32) showed that intracerebral injection of the free radical generating system (hypoxanthine and xanthine oxidase) in rats resulted in structural damage to neurons, increased permeability of the blood-brain barrier, and increased brain water content.

Free radicals stimulate membrane phospholipase activity during ischemia causing the release of polyunsaturated fatty acids. The oxidation of these fatty acids via the cyclooxygenase and lipooxygenase pathways forms thromboxanes, prostaglandins, and leukotrienes that induce chemotaxis, inflammation and more oxygen free radicals (33-36). Free radicals have other sources during ischemia including mitochondrial oxidation (37), lactic acidosis (38), and activated white cells (39). Patt et al. (40) measured hydrogen peroxide in the brains of gerbil exposed to unilateral carotid artery occlusion and reperfusion. Gerbils were fed a tungsten-rich diet to inactivate xanthine oxidase and those who received this diet for 4,5 , and $6 \mathrm{wk}$ developed progressive decreases in brain xanthine oxidase activity. This correlated with decreased cerebral edema and brain hydrogen peroxide levels, suggesting that hydrogen peroxide was derived from xanthine oxidase activity, and that it contributes to reperfusion-induced cerebral edema.

Although results of our study show allopurinol markedly reduced brain water content in the right hemisphere (ipsilateral to the ligation), it had no effect on the left hemisphere. This suggests that the drug does not exert an osmotic influence.

Our results are consistent with the work of Itoh et al. (24) who treated adult rats with large doses of allopurinol $(200 \mathrm{mg} / \mathrm{kg}) 24$ and again $1 \mathrm{~h}$ before $4 \mathrm{~h}$ of reversible cerebral ischemia. The study showed that cerebral water content $1 \mathrm{~h}$ after reperfusion was reduced with allopurinol. The findings were accompanied by significantly improved survival rates. Pigott et al. (41) demonstrated that allopurinol treatment prevented death in all six adult rats exposed to $15 \mathrm{~min}$ of global cerebral ischemia, whereas no rats treated with normal saline survived. They also showed that the arachidonic acid content of ischemic brain was reduced by allopurinol pretreatment. Recently, Martz et al. (25) reduced cerebral infarct volume in adult rats by $32-35 \%$ with allopurinol treatment, which was given in doses of $100 \mathrm{mg} / \mathrm{kg} \mathrm{48,24}$, and 1 $\mathrm{h}$ before permanent middle cerebral artery occlusion.

The model of perinatal hypoxic-ischemic brain damage used in this study includes ligation of the right common carotid artery that reduces blood flow in individual structures of the right hemisphere to $16-41 \%$ of normal (42). Although incomplete, this degree of ischemia combined with hypoxia, is severe enough to cause a loss of ATP $(43,44)$ and an accumulation of hypoxanthine (Palmer C, unpublished data). This incomplete ischemia might also have supplied enough oxygen to tissues at the edge of the ischemic zone to permit xanthine oxidase activity or to enable the oxygen requiring cycloxygenase and lipoxygenase enzyme systems to generate eicosanoids and more free radicals (34). Furthermore, oxygen free radicals cause inhibition of mitochondrial respiration (45). In this regard, studies in adult animals have shown a near complete recovery of the cerebral energy state upon recirculation after complete ischemia but not after incomplete ischemia $(46,47)$.

Although much of allopurinol's success in reducing ischemicreperfusion injury has been attributed to its ability to inhibit xanthine oxidase, other mechanisms warrant consideration. The reaction catalyzed by xanthine oxidase is the first irreversible step in the catabolic breakdown of ATP. Inhibition of xanthine oxidase activity by allopurinol might have reduced the depletion of purine bases and enhanced their reconversion to nucleotides. Lasley et al. (48) using a Langendorff isolated heart apparatus, showed that hearts treated with allopurinol exhibit greater ATP levels and improved function during reperfusion following ischemia than controls. Cunningham et al. (49) reported a conservation of ATP and total adenine nucleotides in ischemic kidneys after allopurinol treatment. Relevant to the brain, the key enzyme in the purine salvage pathway, hypoxanthine-guaninephosphoribosyltransferase, which catalyzes the one step formation of nucleotides from hypoxanthine, is found homogeneously in the rat CNS. Moreover, there is a 3 -fold increase in its activity in the first 15 to $20 \mathrm{~d}$ of postnatal life (50). The brain even more than other tissues recycles hypoxanthine and converts it into purine nucleotides (51). In addition, allopurinol ribonucleotide, a metabolite of allopurinol, inhibits $5^{\prime}$ nucleotidase, the enzyme that catalyzes the dephosphorylation of AMP (52). These findings suggest that allopurinol may have enhanced the preservation of adenine cerebral nucleotides, including ATP, during both hypoxia-ischemia and recovery in addition to its inhibition of xanthine oxidase activity.

Of equal or greater interest is the fact that allopurinol and its active metabolite, oxypurinol, are scavengers of free radicals (19, 20). Furthermore, allopurinol has a dose-related inhibitory effect on polymorphonuclear leukocyte lysosomal enzyme release (53). These two dose-related actions are important because of the large doses of allopurinol used in this and other studies that have shown a neuroprotective effect.

In conclusion, we have shown that high dose allopurinol treatment substantially reduces hypoxic-ischemic brain damage in 7-d-old rats. Further studies are required to define its neuroprotective mechanism and its potential for preventing human hypoxic-ischemic brain injury.

Acknowledgments. The authors thank Dr. André du Plessis for his assistance in performing the experiments, Mary Bartholomew for statistical advice, and Tina M. Gingrich for secretarial assistance.

\section{REFERENCES}

1. Kirsch JR, Phelan AM, Lange DG, Traystman RJ 1987 Free radicals detected in brain during reperfusion from global ischemia. Fed Proc 46:799

2. McCord JM 1985 Oxygen-derived free radicals in postischemic tissue injury. N Engl J Med 312:159-163

3. Chan PH, Yurko M, Fishman RA 1982 Phospholipid degradation and cellular edema induced by free radicals in brain cortical slices. J Neurochem 38:525531

4. Demopoulos HB, Flamm E, Seligman M, Pietronigro DD 1982 Oxygen free radicals in central nervous system ischemia and trauma. In: Autor AP (ed) Pathology of Oxygen. Academic Press, New York, pp 127-155

5. Yoshida S, Abe K, Busto R, Watson B, Kogure K, Ginsburg M 1982 Influence of transient ischemia on lipid-soluble antioxidants, free fatty acids and energy metabolites in rat brain. Brain Res 245:307-316

6. Chan PH, Longar S, Fishman RA 1987 Protective effects of liposome-entrapped superoxide dismutase on posttraumatic brain edema. Ann Neurol 21:540-547

7. Thiringer K, Hrbek A, Karlsson K, Rosén KG, Kjellmer I 1987 Postasphyxial cerebral survival in newborn sheep after treatment with oxygen free radical scavengers and a calcium antagonist. Pediatr Res 22:62-66

8. Yoshida S, Busto R, Watson BD, Santiso M, Ginsberg MD 1985 Postischemic cerebral lipid peroxidation in vitro: Modification by dietary vitamin E. J Neurochem 44:1593-1601 
9. Yammamoto $M$, Shima $T$, Uozumi T, Sogabe T, Yamada K, Kawasaki T 1983 A possible role of lipid peroxidation in cellular damages caused by cerebral ischemia and the protective effect of $\alpha$-tocopherol administration. Stroke 14:977-982

10. Watson BD, Busto R, Goldberg WJ, Santiso M, Yoshida S, Ginsberg MD 1984 Lipid peroxidation in vivo induced by reversible global ischemia in rat brain. J Neurochem 42:268-274

11. Berne RM, Rubio R, Curnish RR 1974 Release of adenosine from ischemic brain. Effect on cerebral vascular resistance and incorporation into cerebral adenine nucleotides. Circ Res 35:262-271

12. Kleihues P, Kobayashi K, Hossmann KA 1974 Purine nucleotide metabolism in the cat brain after one hour of complete ischemia. J Neurochem 23:417425

13. Harkness RA, Lund RJ 1983 Cerebrospinal fluid concentrations of hypoxanthine, xanthine, uridine and inosine: high concentrations of the ATP metabolite hypoxanthine after hypoxia. J Clin Pathol 36:1-8

14. Saugstad OD 1988 Hypoxanthine as an indicator of hypoxia: its role in health and disease through free radical production. Pediatr Res 23:143-150

15. Hagberg H, Andersson P, Lacarewicz J, Jacobson I, Butcher S, Sandberg M 1987 Extracellular adenosine, inosine, hypoxanthine, and xanthine in relation to tissue nucleotides and purines in rat striatum during transient ischemia. J Neurochem 49:227-231

16. Watson BD, Busto R, Goldberg WJ, Santiso M, Yoshida S, Ginsberg MD 1984 Lipid peroxidation in vivo induced by reversible global ischemia in rat brain. J Neurochem 42:268-274

17. Freeman BA, Crapo JD 1982 Biology of disease. Lab Invest 47:412

18. Kellogg EW, Fridovich I 1975 Superoxide, hydrogen peroxide and singlet oxygen in lipid peroxidation by a xanthine oxidase system. $J$ Biol Chem 250:8812-8817

19. Moorhouse PC, Grootveld M, Halliwell B, Quinlan JG, Gutteridge JMC 1987 Allopurinol and oxypurinol are hydroxyl radical scavengers. FEBS Lett 213:23-28

20. Das DK, Engelman RM, Clement R, Otani H, Prasad MR, Rao PS 1987 Role of xanthine oxidase inhibition as free radical scavenger: a novel mechanism of action of allopurinol and oxypurinol in myocardial salvage. Biochem, Biophys Res Commun 148:314-319

21. Werns SW, Shea MJ Mitsos SE, Dysko RC, Fantone JC, Schork MA, Abram GD Pitt B, Lucchesi BR 1986 Reduction of the size of infarction by allopurinol in the ischemic-reperfused canine heart. Circulation 73:518-524

22. Baker GL, Corry RJ, Autor AP 1988 Oxygen free radical induced damage in kidneys subjected to warm ischemia and reperfusion. Ann Surg 202:628641

23. Parks DA, Bulkley GB, Granger DN, Hamilton SR, McCord JM 1982 Ischemic injury in the cat small intestine: role of superoxide radicals. Gastroenterology $82: 9-15$

24. Itoh T, Kawakami M, Yamauchi Y, Shimizu S, Nakamura M 1986 Effect of allopurinol on ischemia and reperfusion-induced cerebral injury in spontaneously hypertensive rats. Stroke 17:1284-1287

25. Martz D, Rayos G, Schielke GP, Betz AL 1989 Allopurinol and dimethylthiourea reduce brain infarction following middle cerebral artery occlusion in rats. Stroke 20:488-494

26. Rice JE, Vannucci RC, Brierley JB 1981 The influence of immaturity on hypoxic-ischemic brain damage in the rat. Ann Neurol 9:131-141

27. Gelman AG, Goodman LS, Rall TW, Murad F (eds) 1985 The Pharmacologic Basis of Therapeutics, 7th ed. MacMillan Publishing Co., New York, pp 710-711

28. Mujsce DJ, Boyer MA, Vannucci RC $1987 \mathrm{CBF}$ and brain edema in perinatal cerebral hypoxia-ischemia. Pediatr Res 21:494A(abstr)

29. Del Maestro RF, Björk J, Arfors K-3 1981 Increase in microvascular permeability induced by enzymatically generated free radicals. Microvasc Res 22:239-254
30. Betz AL 1985 Identification of hypoxanthine transport and xanthine oxidase activity in brain capillaries. J Neurochem 44:574-579

31. Zweier JL Kuppusamy P, Lutty GA 1988 Measurement of endothelial cell free radical generation: Evidence for a central mechanism of free radical injury in postischemic tissues. Proc Natl Acad Sci USA 85:4046-4050

32. Chan PH, Schmidley JW, Fishman RA, Longar SM 1984 Brain injury, edema, and vascular permeability changes induced by oxygen-derived free radicals. Neurology 34:315-320

33. Ellis EF, Wright KF, Wei EP, Kontos HA 1983 Cyclooxygenase products of arachidonic acid metabolism in cat cerebral cortex after experimental concussive brain injury. $J$ Neurochem 37:892

34. Moskowitz MA, Kiwak KJ, Herkimin K, Levine L 1984 Synthesis of compounds with properties of leukotrienes $\mathrm{C}$ and $\mathrm{D}$ in gerbil brains after ischemia and reperfusion. Science 224:886

35. Gaudet RJ, Levine L 1979 Transient cerebral ischemia and brain prostaglandins. Biochem Biophys Res Commun 86:893-901

36. Chan PH, Fishman RA 1980 Transient formation of superoxide radicals in polyunsaturated fatty acid-induced brain swelling. J Neurochem 35:10041007

37. Boveris A, Chance B 1973 The mitochondrial generation of hydrogen peroxide. Biochem J 134:707

38. Siesjö BK, Bendek G, Koide T, Westerberg E, Wieloch $T 1985$ Influence of acidosis on lipid peroxidation in brain tissues in vitro. J Cereb Blood Flow Metabol 5:253-258

39. Babior BM 1978 Oxygen-dependent microbial killing by pheyocytes, part I. N Engl J Med 298:659-668

40. Patt A Harken AH Burton LK, Rodell TC, Piermattei D, Schorr WJ, Parker NB, Berger EM, Horesh IR; Terada LS, Linas SL, Cheronis JC, Repine JE 1988 Xanthine oxidase-derived hydrogen peroxide contributes to ischemia reperfusion-induced edema in gerbil brains. J Clin Invest 81:1556-1562

41. Pigott JP, Donovan DL, Fink JA, Sharp WV 1988 Experimental pharmacologic cerebroprotection. J Vasc Surg 7:625-630

42. Vannucci RC, Lyons DT, Vasta F 1988 Regional cerebral blood flow during hypoxia-ischemia in immature rats. Stroke 19:245-250

43. Palmer C Brucklacher RM, Vannucci RC 1990 Energy balance in perinatal hypoxic-ischemic brain damage. J Cereb Blood Flow Metabol (in press)

44. Welsh FA, Vannucci RC, Brierley JB 1982 Columnar alterations of NADH fluorescence during hypoxia-ischemia in immature rat brain. J Cereb Blood Flow Metab 2:211-228

45. Hillered L Ernster L 1983 Respiratory activity of isolated rat brain mitochondria following in vitro exposure to oxygen radicals. J Cereb Blood Flow Metab 3:207

46. Rehncrona S, Mela L, Siesjö BK 1979 Recovery of brain mitochondrial function in the rat after complete and incomplete cerebral ischemia. Stroke $10: 437-446$

47. Siesjö BK 1981 Cell damage in the brain. A speculative synthesis. J Cereb Blood Flow Metab 1:155-185

48. Lasley RD, Ely SW, Berne RM, Mentzer RM 1988 Allopurinol enhanced adenine nucleotide repletion after myocardial ischemia in the isolated rat heart. Am Soc Clin Invest 81:16-20

49. Cunningham SK, Keaveny TV, Fitzgerald P 1974 Effect of allopurinol on tissue ATP, ADP and AMP concentrations in renal ischemia. $\mathrm{Br} \mathrm{J}$ Surg 61:562-565

50. Gutensohn W, Guroff G 1972 Hypoxanthine-guanine phosphoribosyltransferase from rat brain (purification, kinetic properties, development and distribution). J Neurochem 19:2139

51. Spector R 1988 Hypoxanthine transport and metabolism in the central nervous system. J Neurochem 50:969-978

52. Fox I, Marchant P 1976 Purine catabolism in man: Inhibition of $5^{\prime}$ phosphomonoenterase activities from placental microsomes. Can J Biochem 54:1055-1060

53. Mikulikova D, Bosmansky K, Bosak V, Ondrasik M 1989 The effect of allopurinol on lysosomal enzyme release. J Rheumatol 48:26-29 